\title{
Evaluation of MRI Findings in Tension Type Headache Patients
}

\author{
SC Sanjay ${ }^{\circledR 1}$, Harshavardhan ${ }^{2}$, Meraj ${ }^{\odot 3}$ \\ 1Professor \& HOD, Department of Radiology, KIMS, Hyderabad, Telangana, India, ${ }^{2}$ Assistant Professor, Department of Radiology, KIMS, Hyderabad, Telangana, India, \\ ${ }^{3}$ Post Graduate Student, Department of Radiology, KIMS, Hyderabad, Telangana, India.
}

\section{Abstract}

Background: Tension-type headache (TTH) has a life-time prevalence of up to $78 \%$ in the general population. It is characterized by bilateral location, pressing/tightening quality and is typically of mild to moderate intensity. Hence; the present study was conducted for evaluation of MRI findings in tension type headache patients. Subjects and Methods: A total of 12 patients with tension type headache were enrolled. Complete demographic details of all the patients were recorded. Relevant history, clinical examination and routine investigations were done. Patients underwent MRI investigations. MR imaging findings were compiled as per proforma and subjected to analysis using SPSS software. Chi-square test was used for assessment of level of significance. Results: Significant abnormal MRI findings were found to be present in 1 patient with tension type headache. The patients with significant MRI finding showed few small discrete T2 and T2 flair Hyperintensities in subcortical white matter. Conclusion: Patients with tension type headache should be viewed with suspicion and MRI should be done for excluding other potential etiologic factors.

Keywords: Magnetic resonance imaging, Tension type headache.

Corresponding Author: SC Sanjay, Professor \& HOD, Department of Radiology, KIMS, Hyderabad, Telangana, India. E-mail: hkps0320@gmail.com

Received: 21 November 2019

\section{Introduction}

Headache is a common clinical feature in patients in the emergency room and in general neurology clinics. Chronic headache is one of the common presenting complaints in patients attending the out patient's department or emergency care of any hospital or general practitioner however, only about $10 \%$ of patients with recurrent headache have secondary cause. Non-acute (chronic) headache is defined as all headache syndromes lasting for at least four weeks. ${ }^{[1-3]}$

From an Indian perspective, few studies describe the epidemiology of headache disorders. Previously, these disorders have been investigated only within larger neuroepidemiological surveys that have neither focused on headache nor used internationally accepted criteria for headache diagnoses. ${ }^{[4]}$

Neuroimaging should be performed, however, on those suspected of an underlying disorder based on the presence of additional symptoms and signs that do not fit the clinical diagnosis of primary headache (e.g., atypical headache patterns, a history of seizures, and/or focal neurological symptoms or signs). Magnetic resonance imaging (MRI) is a medical imaging technique used to aid diagnosis but unlike CT it does not use ionizing radiation. Tension-type headache (TTH) has a life-time prevalence of up to $78 \%$ in the general population. It is characterized by bilateral location, pressing/tightening quality and is typically of mild to moderate intensity. ${ }^{[5,6]}$

Hence; the present study was conducted for evaluation of MRI findings in tension type headache patients.

\section{Subjects and Methods}

The present study was conducted in the department of Radiodiagnosis and it included assessment of MRI findings in tension type headache patients. Ethical approval was obtained from institutional ethical committee and written consent was obtained from all the patients after explaining in detail the entire research protocol. A total of 12 patients with tension type headache were enrolled. Complete demographic details of all the patients were recorded.

\section{Inclusion Criteria}

- Patients with chief complaint of non-acute headache with diagnosis of tension type headache.

- Patient willing to give inform written consent to take part in the study. 


\section{Exclusion Criteria}

- Patients of acute head injury and history of neurosurgery.

- Patients who refused to give the informed consent.

Relevant history, clinical examination and routine investigations were done. Patients underwent MRI investigations. MR imaging findings were compiled as per proforma and subjected to analysis using SPSS software. Chi-square test was used for assessment of level of significance. P- value of less than 0.05 was taken as significant.

\section{Results}

In the present study, a total of 12 patients with tension type headache were analysed. Mean age of the patients of the present study was 38.4 years. 33.34 percent of the patients belonged to the age group of 31 to 40 years. 58.33 percent of the patients of the present study were females while the remaining were males.

In the present study, significant abnormal MRI findings were found to be present in 1 patient with tension type headache. The patients with significant MRI finding showed few small discrete T2 and T2 flair Hyperintensities in subcortical white matter.

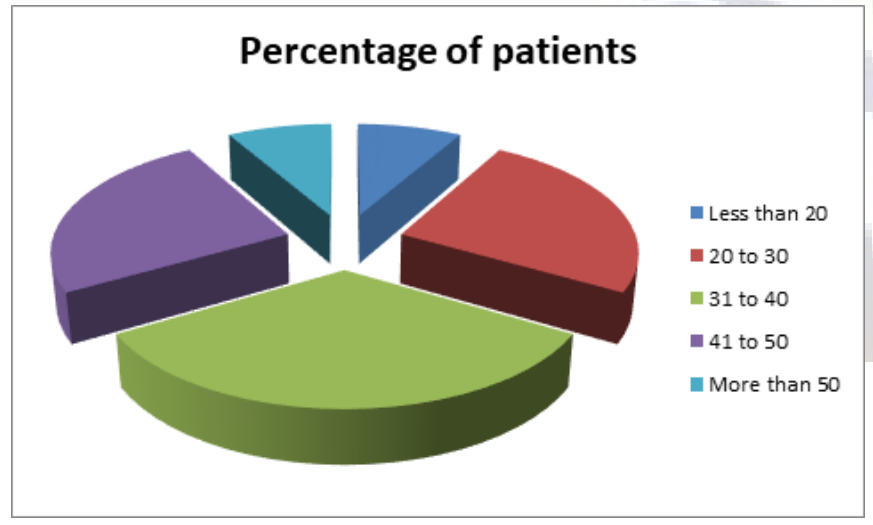

Figure 1: Age-wise distribution of patients

\section{Discussion}

Primary headache is the majority of headache patients presenting to a primary care practice. Approximately $0.1 \%$ of headaches are sinister. Among patients with migraine and a normal neurological examination, the prevalence of significant intracranial abnormalities on neuroimaging ranges from 0 to $3.1 \%$ and combining this data in a meta-analysis resulted in a prevalence of $0.18 \%$. The underlying cause of tension-type headache is uncertain. Activation of hyperexcitable peripheral

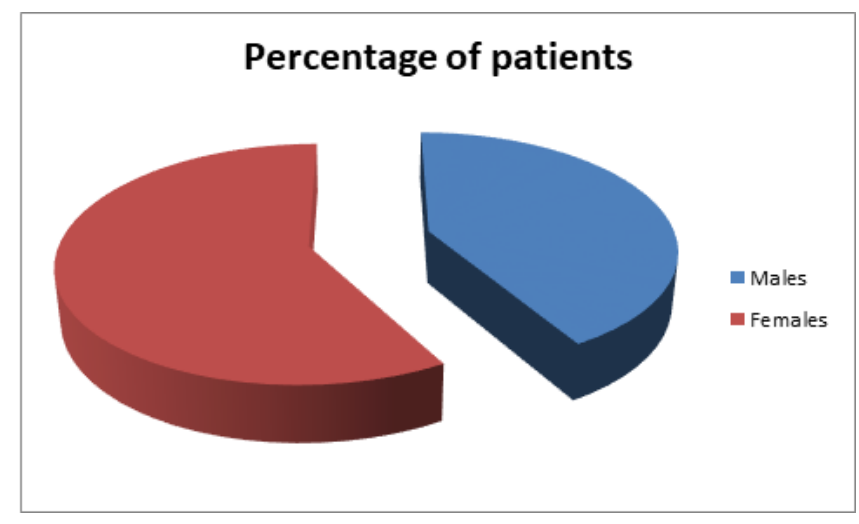

Figure 2: Gender-wise distribution of patients

afferent neurons from head and neck muscles is the most likely explanation for episodes of infrequent tension-type headache. Muscle tenderness and psychological tension are associated with and aggravate tension-type headache but are not clearly its cause. Abnormalities in central pain processing and generalised increased pain sensitivity are present in some patients with tension-type headache. Susceptibility to tensiontype headache is influenced by genetic factors. ${ }^{[7-9]}$

In the present study, a total of 12 patients with tension type headache were analysed. Mean age of the patients of the present study was 38.4 years. 33.34 percent of the patients belonged to the age group of 31 to 40 years. 58.33 percent of the patients of the present study were females while the remaining were males. Yılmaz $\ddot{U}$ et al determined headache types and to evaluate the frequency and clinical significance of brain MRI abnormalities in children with headache. A total of 449 children (261 male and 188 female with a mean age of $11.16 \pm 3.22$ years) with headache were included into the study. The causes of headache were migraine in $247(55.0 \%)$, tension-type in $133(29.6 \%)$, secondary in $48(10.7 \%)$, and unspecified headaches in 21 $(4.7 \%)$ patients. Overall, $324(72.2 \%)$ patients underwent cerebral MRI, which revealed abnormalities in $68(21.0 \%)$ patients. Two $(0.6 \%)$ patients had cerebral MRI abnormalities relevant to headache, including tumor and hydrocephalus each $1(0.3 \%)$. Twenty-nine $(8.9 \%)$ patients had incidental cerebral MRI abnormalities including 14 (4.3\%) white-matter hyperintensities, $4(1.2 \%)$ old infarcts, 3 (0.9\%) Chiari malformations, arachnoid cysts and demyelinating lesions each $2(0.6 \%)$, and subdural hygroma, fibrous dysplasia, pineal cyst and perivascular widening, each 1 (0.3\%). Remaining $36(11.1 \%)$ patients had extra-cerebral MRI abnormalities including $34(10.5 \%)$ sinus disease, and $2(0.6 \%)$ adenoid vegetation. Indications for brain MRI were atypical headache pattern or presence of neurologic abnormalities in $59(18.2 \%)$ patients and parents' concerns in $265(81.8 \%)$ patients. The 


\begin{tabular}{|c|c|c|c|c|c|c|}
\hline \multirow[t]{2}{*}{ Parameter } & $\begin{array}{l}\text { Presence of } \\
\text { MRI findings }\end{array}$ & \multirow{2}{*}{$\begin{array}{l}\text { significant } \\
\text { Percentage } \\
\text { of } \\
\text { patients }\end{array}$} & \multicolumn{2}{|c|}{$\begin{array}{l}\text { Absence of significant MRI find- } \\
\text { ings }\end{array}$} & \multicolumn{2}{|l|}{ Total } \\
\hline & $\begin{array}{l}\text { Number of } \\
\text { patients }\end{array}$ & & $\begin{array}{l}\text { Number of } \\
\text { patients }\end{array}$ & $\begin{array}{l}\text { Percentage of } \\
\text { patients }\end{array}$ & $\begin{array}{l}\text { Number of } \\
\text { patients }\end{array}$ & $\begin{array}{l}\text { Percentage of } \\
\text { patients }\end{array}$ \\
\hline Tension type & 1 & 8.33 & 11 & 91.67 & 12 & 100 \\
\hline Chi- square value & 102.33 & & & & & \\
\hline p-value & 0.087 & & & & & \\
\hline
\end{tabular}

Table 2: MRI findings in tension type headache patients

\begin{tabular}{|c|c|c|c|c|c|}
\hline $\begin{array}{l}\text { Number } \\
\text { patients }\end{array}$ & of $\quad \mathrm{T} 1$ & T2 & T2 FLAIR & DWI & SWI \\
\hline 1 & - & $\begin{array}{l}\text { Hyperintensities } \\
\text { in subcortical } \\
\text { white matter }\end{array}$ & $\begin{array}{l}\text { Hyperintensities } \\
\text { in subcortical } \\
\text { white matter }\end{array}$ & - & - \\
\hline
\end{tabular}

rates of abnormal MRI findings were similar between these 2 groups. The most frequent cause of headache in children is migraine. Despite the high rate of imaging abnormalities, the yield of brain MRI was not contributory to the diagnostic and therapeutic approach. ${ }^{[10]}$

In the present study, significant abnormal MRI findings were found to be present in 1 patient with tension type headache. The patients with significant MRI finding showed few small discrete T2 and T2 flair Hyperintensities in subcortical white matter. Gurkasa E et al described the findings on magnetic resonance imaging $(\mathrm{MRI})$ in children with headache. A total of 478 patients (273 female, 205 male) were admitted with the complaint of headache. The types of headache were migraine in $218(45.6 \%)$, tension-type in $159(33.3 \%)$, secondary in $39(8.2 \%)$ and unspecified headaches in $62(13 \%)$ patients. Brain MRI was performed in 407 (85\%) patients and revealed cerebral abnormalities in 128 (31.4\%) patients; 5 patients had cerebral abnormalities relevant with headache, including tumors. Amongst the others 123 patients, the most common findings were 42 cases $(10 \%)$ of nonspecific white matter abnormalities, 17 cases (4\%) of enlarged perivascular spaces, 17 cases (4\%) of arachnoid cyst, 16 cases $(3.9 \%)$ of asymmetric ventricles, 12 cases $(2.9 \%)$ with Chiari type I and cerebellar tonsillar ectopia. Also, 17 (4.1\%) patients had extra-cerebral MRI abnormalities including sinusitis, mucosal thickening and retention cysts of sinuses. The contribution of brain MRI in the diagnosis and management of the children with headache was still low. ${ }^{[11]}$

\section{Conclusion}

From the above results, the authors conclude that patients with tension type headache should be viewed with suspicion and
MRI should be done for excluding other potential etiologic factors.

\section{References}

1. Stovner LJ, Hagen K, Jensen R, Katsarava Z, Lipton RB, Scher AI, et al. The Global Burden of Headache: A Documentation of Headache Prevalence and Disability Worldwide. Cephalalgia. 2007;27(3):193-210. Available from: https://dx.doi.org/10. 1111/j.1468-2982.2007.01288.x.

2. Vos T, Flaxman AD, Naghavi M, Lozano R, Michaud C, Ezzati M. Years lived with disability (YLDs) for 1160 sequelae of 289 diseases and injuries 1990-2010: a systematic analysis for the Global Burden of Disease Study. Lancet. 2010;380:2163-2196.

3. Ravishankar K, Chakravarthy A. Headache - the Indian experience. Ann Indian Acad Neurol. 2002;5:107-112.

4. Goadsby PJ. To scan or not to scan in headache. BMJ. 2004;329:469-470. Available from: https://dx.doi.org/10. 1136/bmj.329.7464.469.

5. Morimatsu M. Classification of chronic headache. Jpn Med Assoc J. 2002;128(11):1607-1610.

6. Osborn RE, Alder DC, Mitchell CS. MR Imaging of the Brain in Patients with Migraine Headaches. Am J Neuroradiol. 1991;12(3):521-525.

7. Francis MV. Neuroimaging in Headache Disorders. J Headache Pain Manag. 2017;2:1-1.

8. Rai GS, Rai T, Jain L, Vyas MM, Roshan R. Evaluation of CT and MRI Findings among Patients Presented with Chief Complaint of Headache in Central India. J Clin Diagn Res. 2016;10(2):21-21. Available from: https://dx.doi.org/10.7860/ JCDR/2016/16852.7249.

9. Lucato LT, Guedes MS, Sato JR, Bacheschi LA, Machado LR, Leite CC. The Role of Conventional MR Imaging Sequences in the Evaluation of Neurocysticercosis: Impact on Characterization of the Scolex and Lesion Burden. Am J 
Neuroradiol. 2007;28(8):1501-1504. Available from: https: //dx.doi.org/10.3174/ajnr.a0623.

10. Yılmaz Ü, Çeleğen M, Yılmaz TS, Gürçınar M, Ünalp A. Childhood headaches and brain magnetic resonance imaging findings. Eur J Paediatr Neurol. 2009;18(2):163-170. Available from: https://doi.org/10.1016/j.ejpn.2013.11.003.

11. Gurkasa E, Karalok ZS, Taskın BD, Aydogmus U, Yılmaz C, Bayram G. Brain magnetic resonance imaging findings in children with headache. Arch Argent Pediatr. 2017;115(6):349355. Available from: https://doi.org/10.5546/aap.2017.eng. e349.

Copyright: (C) the author(s), 2020. It is an open-access article distributed under the terms of the Creative Commons Attribution License (CC BY 4.0), which permits authors to retain ownership of the copyright for their content, and allow anyone to download, reuse, reprint, modify, distribute and/or copy the content as long as the original authors and source are cited.

How to cite this article: Sanjay SC, Harshavardhan , Meraj . Evaluation of MRI Findings in Tension Type Headache Patients. Asian J. Med. Radiol. Res. 2020;8(1):150-153.

DOI: dx.doi.org/10.47009/ajmrr.2020.8.1.27

Source of Support: Nil, Conflict of Interest: None declared. 